\title{
Can Ultrasound or pH Influence Pd Distribution on the Surface of HAP to Improve Its Catalytic Properties in the Dry Reforming of Methane?
}

\author{
Joanna Kamieniak ${ }^{1} \cdot$ Elena Bernalte $^{1,2} \cdot$ Aidan M. Doyle $^{1} \cdot$ Peter J. Kelly $^{1}$. \\ Craig E. Banks ${ }^{1}$
}

Received: 3 April 2017 / Accepted: 8 June 2017 / Published online: 19 June 2017

(C) The Author(s) 2017. This article is an open access publication

\begin{abstract}
The influence of ultrasound and different $\mathrm{pH}$ pre-treatments during the metal doping/modification of a hydroxyapatite (HAP) support is investigated. HAP is first synthesised via a hard-template synthetic route using carbon nanorods followed by their full physiochemical characterisation. The HAP was found to be crystalline and comprised a mesoporous structure as observed via XRD and nitrogen adsorption with a BET surface area of 97.57 $( \pm 1.16) \mathrm{m}^{2} \mathrm{~g}^{-1}$. Ultrasound-assisted ion exchange (IE) and incipient wetness impregnation (IW) methodologies were employed to decorate the surface of HAP with $\mathrm{Pd}^{0}$ and are compared to previous procedures. The influence of $\mathrm{pH}$ upon the distribution of $\mathrm{Pd}^{0}$ throughout the samples during the doping process is also studied. All the prepared
\end{abstract}

samples were evaluated for their catalytic activity towards dry reforming of methane (DRM) and the reaction was monitored via a thermal conductivity detector, coupled with gas chromatography (GC-TCD). It was found that ultrasound-assisted IE significantly accelerated the process from 3 days to $3 \mathrm{~h}$ and with the $\mathrm{Pd}^{0}$ metal remaining highly distributed upon the HAP with minor changes in catalytic conversions. Moreover, the ultrasound-assisted IW method successfully improved the $\mathrm{Pd}^{0}$ distribution and catalytic performance. On the other hand, the dispersion of the metal was unaffected after $\mathrm{pH}$ treatments in IE with no catalytic improvements observed, in contrast to IW, where considerable increase in metal distribution and subsequently catalytic performance was observed.

Electronic supplementary material The online version of this article (doi:10.1007/s10562-017-2114-5) contains supplementary material, which is available to authorized users.

Aidan M. Doyle

a.m.doyle@mmu.ac.uk

$\triangle$ Craig E. Banks

c.banks@mmu.ac.uk

http://www.craigbanksresearch.com

1 Faculty of Science and Engineering, Manchester

Metropolitan University, Chester Street,

Manchester M1 5GD, UK

2 Departamento de Química Analítica e IACYS, Facultad de Ciencias, Universidad de Extremadura, Avda. de Elvas s/n, 06006 Badajoz, Spain 


\section{Graphical Abstract}

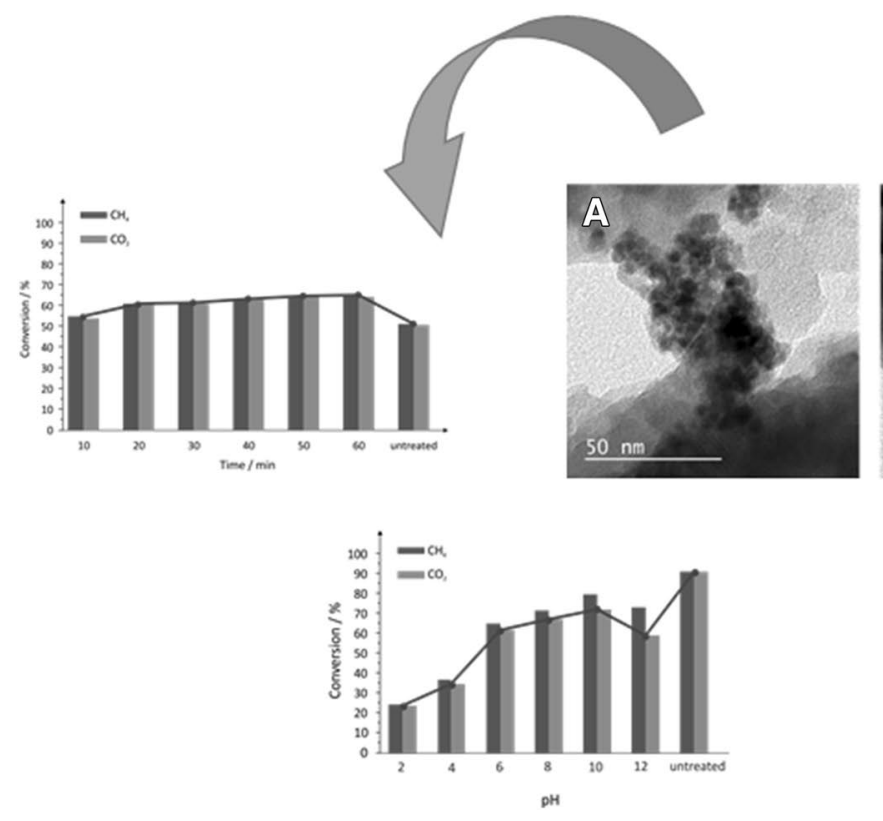

Keywords Methane decomposition · Hydroxyapatite . Solvent effects · Ultrasound

\section{Introduction}

Methane $\left(\mathrm{CH}_{4}\right)$, a principal component of natural gas, is an abundant hydrocarbon resource that is employed as a relatively inexpensive and clean-burning fuel $[1,2]$. It is also used in the dry reforming of methane (DRM) to produce synthesis gas (carbon monoxide and hydrogen), a key intermediate in the chemical industry in the preparation of higher hydrocarbons, alcohols and aldehydes [3]. Besides many potential applications of $\mathrm{H}_{2}$ in different fields, the produced $\mathrm{CO}$ can be used in e.g. carbonylation reactions of organic compounds [4-7] summarised in a review by Veige et al. [8] Due to the high thermal stability of $\mathrm{CH}_{4}$ and $\mathrm{CO}_{2}$, the DRM reaction is highly endothermic (Eq. 1), and needs an external energy source, usually high temperatures $[1,9]$.

$$
\mathrm{CH}_{4}+\mathrm{CO}_{2} \leftrightarrow 2 \mathrm{CO}+2 \mathrm{H}_{2}, \quad \Delta \mathrm{H}^{\circ}=+247 \mathrm{~kJ} \mathrm{~mol}^{-1}
$$

DRM is typically carried out over supported noble metal catalysts to reduce the activation energy and enhance the reaction at lower temperatures [10]. Nevertheless, the key step during the process is the activation of $\mathrm{CH}_{4}$, which occurs on the surface of the active metal; thus the distribution of metal throughout the catalytic support plays a significant role. Recent studies have focused on the preparation
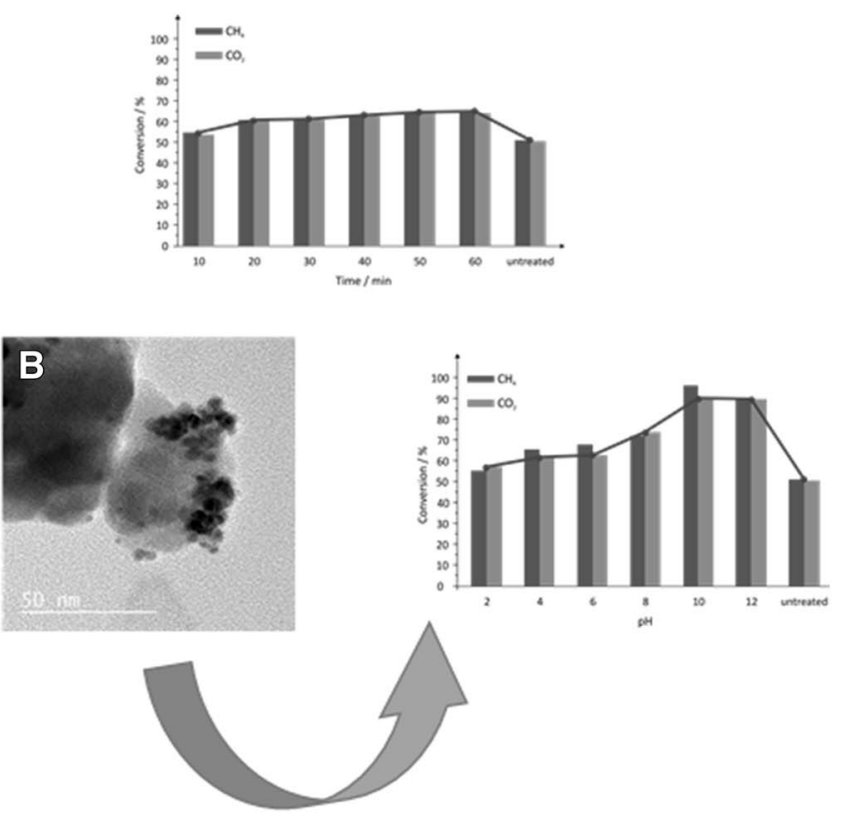

of active and stable catalysts that are less sensitive to sintering and exhibit acid-base properties [11-21]. For example, transition metal based catalysts were reported by Ren et al. in the reforming of $\mathrm{CH}_{4}$. They employed $\mathrm{Ni} / \mathrm{SiO}_{2}$ catalysts, which exhibited $50 \%$ methane conversion at $750{ }^{\circ} \mathrm{C}$, over $15 \mathrm{~h}$ of stream reaction [22]. Shang et al. also applied Ni metal for DRM, but used $\gamma-\mathrm{Al}_{2} \mathrm{O}_{3}$ as a support, with no $\mathrm{CH}_{4}$ conversion observed at $850^{\circ} \mathrm{C}$ for the first $10 \mathrm{~h}$, and 99\% conversion over the following $140 \mathrm{~h}$ of reaction [23]. However, transition metal based catalysts have been found to be less resistant to the coking process when compared to noble metals [24]. On the other hand, it has been shown that metal-support interaction plays a crucial role in controlling the particle size, coking process and oxygen availability of the catalyst. As demonstrated by Singha et al. strong interactions promote small and highly dispersed particles, making the catalyst more resistant to sintering and giving improved oxygen availability [25]. Hence, optimal metal dispersion throughout/over the catalyst support may enhance catalytic activity towards the DRM reaction.

Catalytic processes using hydroxyapatite [HAP, $\left.\mathrm{Ca}_{10}\left(\mathrm{PO}_{4}\right)_{6}(\mathrm{OH})_{2}\right]$ as a metal support have been extensively studied. HAP possesses both acidic and basic sites. It has a hexagonal crystal structure with the $\mathrm{P}_{3} / \mathrm{m}$ space group and well-known $1.67 \mathrm{Ca}: \mathrm{P}$ ratio [26]. The introduction of metal to HAP is crucial towards its catalytic activity, as described widely in the literature [27-41]. Boukha et al. recently reported Pd doped HAP for $\mathrm{CO}$ elimination processes and 
investigated the influence of Pd particle size, with different metal loadings on the activity and selectivity towards $\mathrm{CO}$ oxidation. It was demonstrated that lower metal loading $(0.5 \mathrm{wt} \%)$ and better metal distribution exhibited stronger $\mathrm{CO}$ adsorption, higher reducibility in the presence of $\mathrm{CO}$, and higher oxygen mobility, compared to the higher loaded samples (1 and $2 \mathrm{wt} \%$ ) [28].

The two metal doping methodologies mainly employed are ion exchange (IE) and incipient wetness impregnation (IW) $[28,29,36,37,42,43]$. While both methods give catalytically active materials, IE is generally more reproducible and reliable than IW, which results in relatively non-uniform metal distribution, size and shape [44]. Nevertheless, there are limited reports that investigate optimisation of those methods or how the metal distribution is affected by different parameters. For example, Rego De Vasconcelos et al. produced synthesis gas by DRM over $\mathrm{Ru}$ and Pt supported HAP using different doping methods, however only the Pt doped catalyst prepared using IW was found to be stable [30].

Ultrasonic treatment is a widely available method that has been used during the preparation of heterogeneous catalysts [45]. Irradiation of a liquid with ultrasound causes acoustic cavitation that results in the rapid growth and implosion of bubbles creating intense levels of localised heating and high pressures [46]. Numerous reports confirm that this process affects the transformation/reduction of metal salts in solution to metal nanoparticles e.g. Pt, $\mathrm{Au}, \mathrm{Ru}, \mathrm{Ni}$. The influence of ultrasound on the relatively unstudied Pd catalysts shows that ultrasonic treatment during catalyst synthesis increases both metal dispersion and catalytic activity in olefin hydrogenation, Suzuki-Miyaura coupling and the direct synthesis of hydrogen peroxide [47-49]. To our knowledge, there are no reports in the literature of ultrasonic treatment of Pd catalysts tested in the DRM reaction. In the present study, HAP supported Pd catalysts are prepared using ultrasound-assisted IW and IE methodologies. The catalytic activity of IW prepared samples was increased by the application of ultrasonic irradiation and the pre-treatment of the HAP support in $\mathrm{pH}$ buffer. The catalyst testing data also showed that ultrasonic irradiation accelerated the typically time-consuming IE process.

\section{Experimental Methods}

\subsection{Materials and Chemicals}

All chemicals were obtained from Sigma-Aldrich and used as received without any further purification. All solutions were made using deionised water with resistivity not $<18.2 \mathrm{M} \Omega \mathrm{cm}$.

\subsection{Synthesis of Carbon Nanorods}

Cetyltrimethylammonium bromide (CTAB, $10 \mathrm{~g})$ and $\mathrm{NaOH}(1 \mathrm{~g})$ were dissolved in deionised water $(90 \mathrm{~mL})$ producing a clear solution. Next, tetraethyl orthosilicate (TEOS) $(11 \mathrm{~mL})$ was added, and the mixture heated to $35^{\circ} \mathrm{C}$ and stirred at this temperature for $30 \mathrm{~min}$, during which time a white precipitate formed. The entire contents were placed in a PTFE lined stainless steel autoclave and heated under static conditions for $24 \mathrm{~h}$ at $150^{\circ} \mathrm{C}$. The autoclave was cooled down to room temperature under a flow of cold water. A white precipitate, MCM-48, was recovered by filtration and washed with deionised water, dried and calcined at $550^{\circ} \mathrm{C}$ for $5 \mathrm{~h}$ using a ramp rate of $2^{\circ} \mathrm{C} \mathrm{min}^{-1}$. To synthesise carbon nanorods, the calcined silica template (MCM-48, $1 \mathrm{~g}$ ) was impregnated with an aqueous solution containing sucrose $(1.25 \mathrm{~g})$, concentrated $\mathrm{H}_{2} \mathrm{SO}_{4}$ $(78.87 \mu \mathrm{L})$ and deionised water $(5 \mathrm{~mL})$. The mixture was placed in the drying oven for $6 \mathrm{~h}$ at $100^{\circ} \mathrm{C}$ and a further $6 \mathrm{~h}$ at $160^{\circ} \mathrm{C}$. The sample, which turned dark brown due to partially carbonised sucrose, was impregnated again with the solution of sucrose $(0.8 \mathrm{~g})$, concentrated $\mathrm{H}_{2} \mathrm{SO}_{4}(50.7 \mu \mathrm{L})$ and deionised water $(5 \mathrm{~mL})$, and dried in the oven using the procedure described above. The carbonisation was completed by pyrolysis under a flow of helium $\left(50 \mathrm{~mL} \mathrm{~min}{ }^{-1}\right)$ at $800^{\circ} \mathrm{C}$. The obtained powder was washed twice with $\mathrm{NaOH}$ solution (50:50 ethanol:water) at $100^{\circ} \mathrm{C}$ to remove the silica template, then filtered and dried at $120^{\circ} \mathrm{C}$.

\subsection{Synthesis of HAP}

HAP was prepared using the same procedure we previously reported [50]. Carbon nanorods ( $0.3 \mathrm{~g})$ were suspended in deionised water $(6 \mathrm{~mL})$ and added to a solution of $\left(\mathrm{NH}_{4}\right)_{2} \mathrm{HPO}_{4}(0.4 \mathrm{M}, 100 \mathrm{~mL})$, which was stirred at room temperature $\left(18-22^{\circ} \mathrm{C}\right)$ in a $2 \mathrm{~L}$ beaker. $\mathrm{Ca}\left(\mathrm{NO}_{3}\right)_{2}$ $(0.6 \mathrm{M}, 100 \mathrm{~mL})$ was then added dropwise over one hour, resulting in a 'milky' suspension of HAP. The $\mathrm{Ca} / \mathrm{P}$ molar ratio was kept at 1.67 , corresponding to the stoichiometry of HAP. The $\mathrm{pH}$ was maintained through the addition of $\mathrm{NaOH}(0.1 \mathrm{M})$ within the range 9.4-9.5. This 'milky' suspension was then stirred overnight at room temperature using a magnetic stirring bar. The obtained precipitate was filtered, cleaned alternately with water and ethanol three times, dried in an oven at $65^{\circ} \mathrm{C}$ for $6 \mathrm{~h}$, and then calcined at $550^{\circ} \mathrm{C}$ for a further $2 \mathrm{~h}$.

\subsection{Pd Doped HAP by Ion Exchange (IE)}

Typical ion exchange methodology was employed as a reference as follows: first $\mathrm{Pd}\left(\mathrm{NO}_{3}\right)_{2}(50 \mathrm{mg})$ was dissolved in deionised water $(100 \mathrm{~mL})$. After that, HAP was added $(1 \mathrm{~g})$ 
and stirred for 3 days at room temperature, then filtered and dried in the oven at $60^{\circ} \mathrm{C}$ for $3 \mathrm{~h}$.

To accelerate the IE process, instead of stirring in ambient conditions for 3 days, the solution was treated with ultrasound (UltraWave U95, 50-60 Hz) for $3 \mathrm{~h}$ via the use of an ultrasonic bath. The resulting samples were filtered, dried in an oven at $60^{\circ} \mathrm{C}$ for $3 \mathrm{~h}$ and calcined in air at $550^{\circ} \mathrm{C}$. Three replicates were diligently performed.

To investigate the influence of $\mathrm{pH}$ of the media in which IE takes place, a Britton-Robinson buffer was utilised instead of water at different $\mathrm{pH}(2,4,6,8,10$ and 12). All samples were filtered, dried in the oven at $60{ }^{\circ} \mathrm{C}$ for $3 \mathrm{~h}$ and calcined in air at $550^{\circ} \mathrm{C}$.

\subsection{Pd Doped by Incipient Wetness Impregnation (IW)}

As a reference sample, $\mathrm{Pd}\left(\mathrm{NO}_{3}\right)_{2}(50 \mathrm{mg})$ was dissolved in a minimal amount of deionised water and dripped onto the HAP $(1 \mathrm{~g})$, which was carefully mixed. The obtained yellow-brown powder was dried in the oven at $60^{\circ} \mathrm{C}$ for $3 \mathrm{~h}$ and calcined in air at $550{ }^{\circ} \mathrm{C}$.

For the ultrasound-assisted impregnation, six samples of HAP mixed with Pd in the same proportions as described above (prior to drying and calcination) were placed in volumetric flasks and sonicated from $10 \mathrm{~min}$ to $1 \mathrm{~h}$, taking one sample out every $10 \mathrm{~min}$. All samples were dried in the oven at $60^{\circ} \mathrm{C}$ for $3 \mathrm{~h}$ and calcined in air at $550^{\circ} \mathrm{C}$.

To examine the influence of $\mathrm{pH}$ upon the doping method, HAP was first pre-treated in different $\mathrm{pHs}$ by stirring HAP $(1 \mathrm{~g})$ in Britton-Robinson buffer for $3 \mathrm{~h}$ following the same procedure as for IE ( $\mathrm{pH} \mathrm{2,} \mathrm{4,} \mathrm{6,} \mathrm{8,} 10$ and 12), then filtered and dried. Metal was then dripped onto pre-treated HAP using the standard IW procedure, dried in the oven at $60^{\circ} \mathrm{C}$ for $3 \mathrm{~h}$ and calcined in air at $550{ }^{\circ} \mathrm{C}$.

\subsection{Characterisation of the Materials}

Microscopic images were recorded using a JEOL 3000F high resolution transmission electron microscope (HRTEM) with an accelerating voltage of $300 \mathrm{kV}$. Semi-quantitative chemical analysis on 5 different areas of the same sample was performed by energy-dispersive X-ray spectroscopy (EDAX) using an Apollo 40 SDD instrument. $\mathrm{X}$-ray diffraction (XRD) was conducted in powder spinning mode at ambient conditions using a Panalytical X'Pert Powder diffractometer with $\mathrm{Cu} \mathrm{K}_{\alpha}$ radiation $(\lambda=1.5406 \AA)$. All powder diffraction patterns were recorded with a step size of $0.052^{\circ}$ and a step time of $200 \mathrm{~s}$, using an X-ray tube operated at $40 \mathrm{kV}$ and $30 \mathrm{~mA}$ with a fixed $1 / 2^{\circ}$ antiscatter slit. For low angle measurements of MCM-48 an anti-scatter $1 / 8^{\circ}$ slit with $0.013^{\circ}$ step size was employed. Nitrogen adsorption/desorption measurements were carried out using a Micromeritics ASAP 2020 Surface Analyser at $-196^{\circ} \mathrm{C}$. Samples were degassed under vacuum $\left(\mathrm{p}<10^{-3}\right.$ $\mathrm{Pa}$ ) for $3 \mathrm{~h}$ at $300^{\circ} \mathrm{C}$ prior to analysis. BET surface areas of the samples were calculated in the relative pressure range $0.05-0.30$. The metal content was determined by inductively coupled plasma optical emission spectroscopy (ICPOES) using iCAP6300 after ultrasonic extraction in $\mathrm{HNO}_{3}$ $(5 \%)$.

\subsection{Dry Reforming of Methane}

The catalyst activity of each sample was studied in a quartz fixed bed reactor placed inside a temperature controlled furnace (Carbolite type 3216, Tempatron, PID500/110/330). A sample of catalyst $(0.2 \mathrm{~g})$ was placed in a quartz tube (10 $\mathrm{mm}$ diameter, $1 \mathrm{~mm}$ thickness) between quartz wool

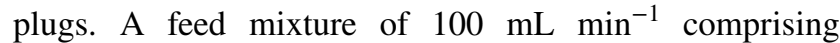
$\mathrm{CH}_{4}: \mathrm{CO}_{2}: \mathrm{He}$ equal to 5:5:90 was used in all catalytic tests. Gases were supplied from lecture bottles (CKGAS filled to 200 bar at $15^{\circ} \mathrm{C}$ ) and regulated using single stage CONCOA 302 series gas regulators. The flow of each gas was maintained using Bronkhorst UK model F-201CV mass flow controllers. Prior to testing, each catalyst was reduced in $30 \mathrm{~mL} \mathrm{~min}{ }^{-1} \mathrm{H}_{2}$ for $1 \mathrm{~h}$ at $300^{\circ} \mathrm{C}$. The reaction products were monitored by a Hewlett Packard 5890 series II gas chromatograph equipped with a GS-GASPRO column $(60 \mathrm{~m} \times 0.32 \mathrm{~mm})$ connected via a 6-way gas sampling valve to a thermal conductivity detector (TCD). Measurements were recorded at $50^{\circ} \mathrm{C}$ intervals (after holding at that temperature for $5 \mathrm{~min}$ ) between 200 and $650^{\circ} \mathrm{C}$ using a heating rate of $10^{\circ} \mathrm{C} \mathrm{min}{ }^{-1}$. The $\mathrm{CH}_{4}$ conversion was calculated as follows:

$\mathrm{CH}_{4}$ conversion $(\%)=\frac{\left(\mathrm{CH}_{4}\right) \text { in }-\left(\mathrm{CH}_{4}\right) \text { out }}{\left(\mathrm{CH}_{4}\right) \text { in }} \times 100$

Conversions of $\mathrm{CH}_{4}$ and $\mathrm{CO}_{2}$ are presented at the highest measured temperature $\left(650^{\circ} \mathrm{C}\right)$.

\section{Results and Discussion}

\subsection{Synthesis and Characterisation of HAP}

All catalysts were prepared as described in the experimental section. HAP was synthesised using a hard template approach utilising mesoporous silica (MCM-48) and carbon nanorods. After each step of the synthesis, the resulting materials were characterised for porosity and crystallinity. First, the XRD pattern revealed the successful formation of MCM-48 with space group Ia3d (Fig. 1). Nitrogen adsorption isotherms were also employed to establish surface characteristics, including Barrett-Joyner-Halenda (BJH) pore size distribution and surface area measurements. As 


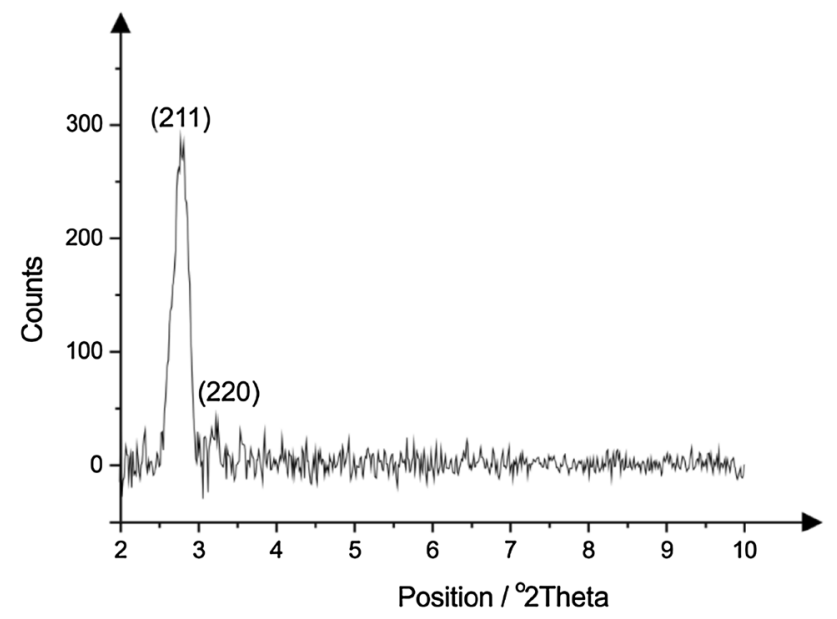

Fig. 1 XRD pattern of MCM-48

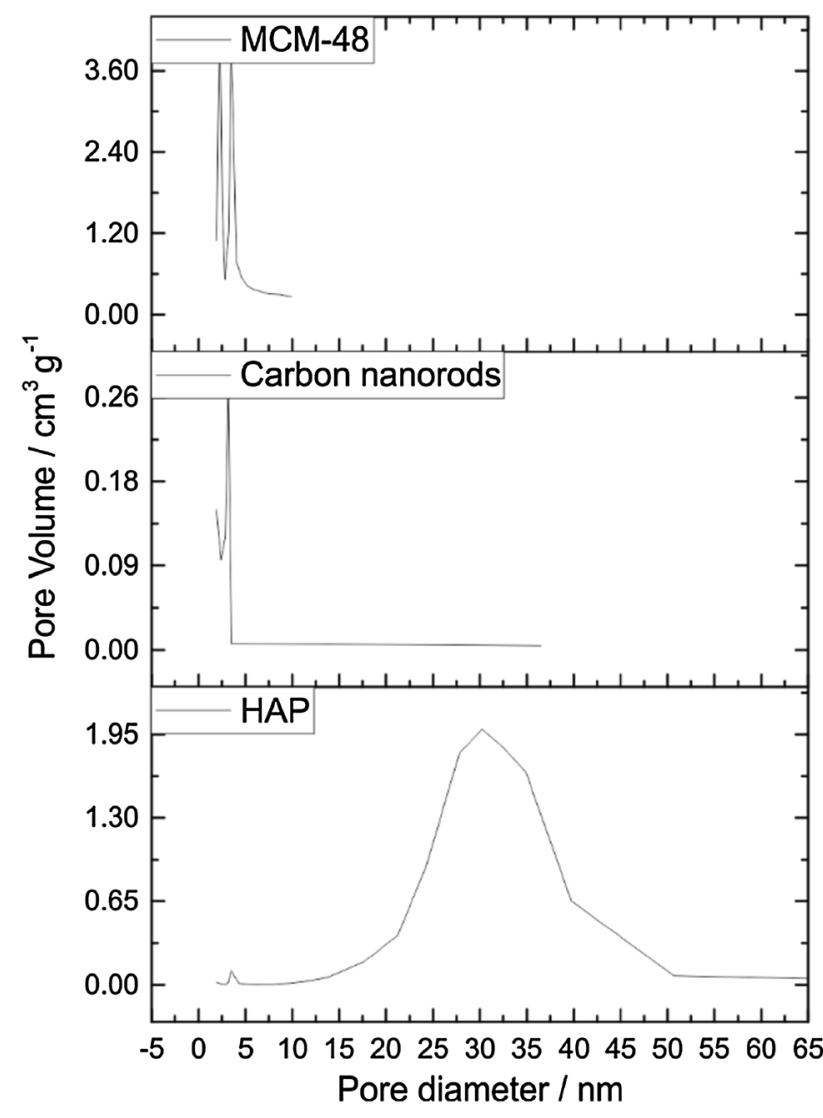

Fig. 2 BJH pore size distribution

shown in Fig. 2, the average surface area of the silica template MCM-48 was $987.9( \pm 44.33) \mathrm{m}^{2} \mathrm{~g}^{-1}$ with an average pore diameter $<5 \mathrm{~nm}$. The carbon nanorods showed an average surface area of $258.22( \pm 5.35) \mathrm{m}^{2} \mathrm{~g}^{-1}$ and around $5 \mathrm{~nm}$ pore diameters, which is similar to those of MCM-48. However, much larger pores were observed in
HAP, with an average pore diameter of $30 \mathrm{~nm}$, along with smaller pores of an average size $<5 \mathrm{~nm}$ present due to the templating effect of carbon nanorods during synthesis. The BET surface area of the mesoporous HAP was 97.57 $( \pm 1.16) \mathrm{m}^{2} \mathrm{~g}^{-1}$. TEM imaging, Fig. 3a, confirmed the presence of mesopores and the characteristic HAP lattice, while the XRD pattern presented in Fig. 3b indicates that all major peaks correspond to hexagonal HAP, when compared to the standard diffraction pattern (JCPDS 09/0432) [51].

\subsection{Ion Exchange (IE)}

The next step after HAP synthesis was to apply Pd onto the surface of the HAP using a standard ion exchange (IE) method. This approach involves stirring the support and metal salt in solution at ambient conditions over the course of a few days. Hence, as this method is time consuming (usually 3 days), ultrasound was employed as an alternative to accelerate the process $(3 \mathrm{~h})$. Three samples were prepared and characterised, along with a control sample (standard IE), using ICP-OES and EDX analysis to measure the Pd loading. The average Pd content, measured by ICP-OES, Table 1, varies between 1.72 and $2.06 \mathrm{wt} \%$ and is lower in all the ultrasound and $\mathrm{pH}$ treated samples than the control. EDX based $\mathrm{Pd} w \mathrm{t} \%$ readings are slightly higher following the application of ultrasound. The catalytic activity of the ultrasound-assisted IE samples towards the DRM reaction was explored using a quartz fixed bed reactor, coupled with a GC-TCD, as described in the experimental section. As presented in Fig. 4, the control sample actually exhibited higher conversions ( $91 \%$ for $\mathrm{CH}_{4}$ and $\mathrm{CO}_{2}$ ) than ultrasound-assisted samples. Even though the concentration of Pd on the surface remains approximately the same, it was noted that, during ultrasonic treatment, water in the ultrasonic bath became warmer. In consequence, $\mathrm{Pd}\left(\mathrm{NO}_{3}\right)_{2}$ becomes more soluble and smaller particles are produced; therefore they are more likely to create agglomerates during the IE process, resulting in a decrease of catalytic activity ( 70\% conversion for $\mathrm{CH}_{4}$ and $\left.\mathrm{CO}_{2}\right)$ possibly due to lower Pd dispersion than the control. However, despite this reduction in activity, ultrasound significantly accelerates the IE process from 3 days to $3 \mathrm{~h}$; hence with careful optimisation of time and temperature, ultrasound-assisted IE can become a beneficial tool for future use/applications with significant time-consuming benefits.

Next, different $\mathrm{pH}$ media were investigated in the IE standard methodology, replacing water with a Britton-Robinson buffer and examining its influence on the catalytic activity towards DRM. Based on the ICP-OES and EDX data (Table 1), the average metal loading remains practically stable throughout the $\mathrm{pH}$ range studied. In fact, the highest metal loading was observed when IE took place in 

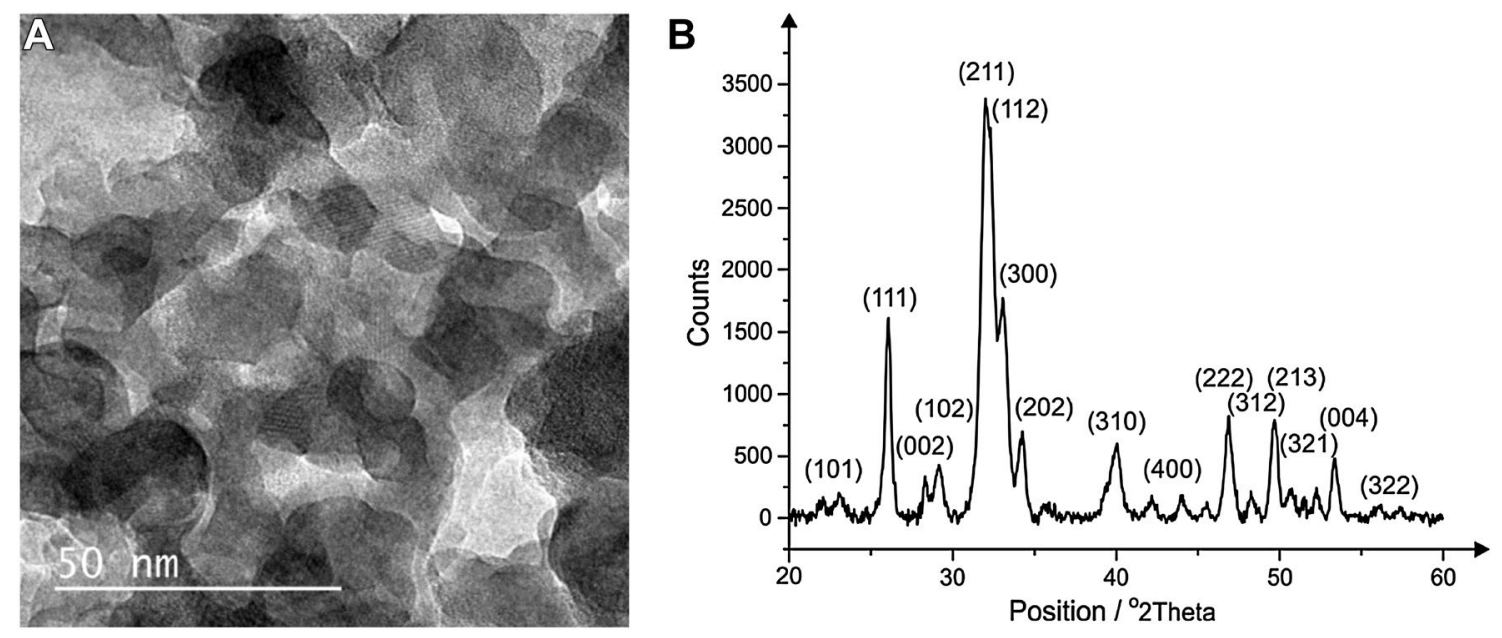

Fig. 3 TEM image (a) and XRD pattern (b) of HAP

Table 1 BET surface areas, ICP-OES, EDX $(N=5)$ average metal loading and standard deviation (SD) for IE preparations

\begin{tabular}{lclll}
\hline & $\begin{array}{c}\text { BET surface } \\
\text { area }\left(\mathrm{m}^{2} \mathrm{~g}^{-1}\right)\end{array}$ & ICP-OES (wt\%) & EDX (wt\%) & SD \\
\hline $\begin{array}{c}\text { Control IE } \\
\text { sample }\end{array}$ & $59.54 \pm 1.29$ & 2.07 & 2.044 & 0.07 \\
$\begin{array}{c}\text { Ultrasound } \\
\text { S1 }\end{array}$ & $74.47 \pm 0.28$ & 2.06 & & \\
S2 & $78.76 \pm 0.29$ & 1.90 & 2.53 & 0.28 \\
S3 & $77.54 \pm 0.28$ & 1.81 & 2.18 & 0.51 \\
pH study & & & 2.81 & 0.44 \\
2 & $144.19 \pm 0.61$ & 1.95 & & \\
4 & $46.99 \pm 0.48$ & - & 2.12 & 0.20 \\
6 & $77.75 \pm 0.23$ & 1.72 & 1.93 & 0.10 \\
8 & $65.61 \pm 0.44$ & 1.93 & 2.01 & 0.15 \\
10 & $67.71 \pm 0.33$ & 2.06 & 2.12 & 0.48 \\
12 & $63.70 \pm 0.38$ & - & 2.03 & 0.32 \\
\hline
\end{tabular}

Endash (-) represents insufficient sample

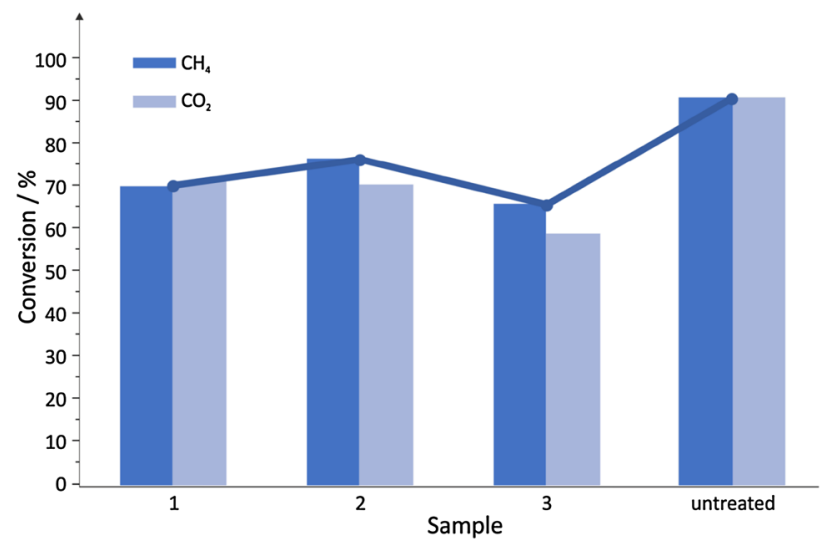

Fig. 4 DRM of ultrasound-assisted IE doped catalysts

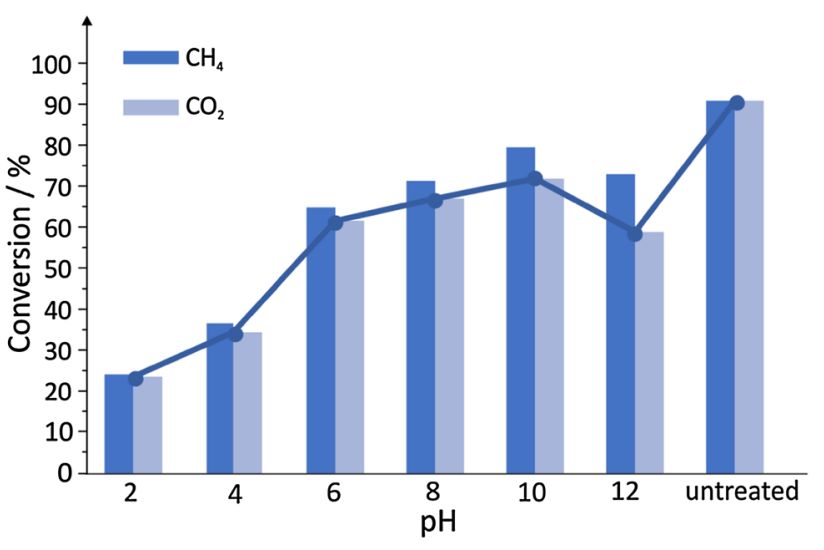

Fig. 5 DRM of IE doped catalysts fabricated using different $\mathrm{pH}$ media

neutral $\mathrm{pH}$ in the control sample (wt $\%=2.07)$. As is also shown in Fig. 5, neutral water media during metal loading is more beneficial in the catalytic reaction of $\mathrm{CH}_{4}$, exhibiting over $90 \% \mathrm{CH}_{4}$ and $\mathrm{CO}_{2}$ conversions. On the other hand, the lowest conversion (24\%) was observed in the strongest acidic media. This can be explained by the higher solubility of the metal and HAP support in the acid, producing small particles that favour interactions between both materials. Even though the metal loading remains unaffected, the formation of clusters due to agglomeration of small particles may significantly reduce the activity of the catalyst. As pH was increased, an improvement in catalytic activity was clearly observed. It is interesting to note that the most active catalyst was obtained after a buffer treatment at $\mathrm{pH}$ 10 (over $80 \% \mathrm{CH}_{4}$ conversion), which is the same $\mathrm{pH}$ that was employed during the synthesis of HAP.

The BET surface areas, Table 1, are higher following the application of ultrasound and pre-treatment in buffer 
solutions (with the exception of $\mathrm{pH} 4$ ). Some samples exhibited different conversions of $\mathrm{CO}_{2}$ to that of $\mathrm{CH}_{4}$. For the untreated sample, the conversion of $\mathrm{CH}_{4}$ was found to be equal to converted $\mathrm{CO}_{2}$. It was due to the $1: 1$ molar ratio of both reactants in the DRM reaction, which suggests that the reaction attained high equilibrium conversions and is selective towards a high yield of syngas without any other products or side reactions. On the other hand, in the case of most of the samples prepared either at different $\mathrm{pH}$ or ultrasound, $\mathrm{CO}_{2}$ conversions were lower than those of $\mathrm{CH}_{4}$. It may be that methane did not fully undergo activation through its dissociation, but also proceeded through thermal cracking due to the high temperature of the reaction [14].

\subsection{Incipient Wetness Impregnation (IW)}

Another metal loading methodology studied here was incipient wetness impregnation (IW). A typical IW approach employs the addition of metal dissolved in a minimum amount of water onto the solid support, followed by evaporation of excess water. In general, IE is a more reproducible method and results in more homogenous metal loading, due to stable doping conditions where all the support is exposed to the metal in the solution, unlike in the IW procedure, which provides random metal deposition (ESI Fig. 1).

In order to have more control over the dispersion of metal throughout the support in the IW approach, ultrasound was utilised over the time range from 10 to $60 \mathrm{~min}$. Pd metal loading was measured by ICP-OES and EDX for six samples prepared using the ultrasound-assisted IW method and a control sample prepared via a standard IW protocol, Table 2. Longer sonication times are accompanied by decreased EDX metal loadings. The fact that no such trend is observed for ICP-OES readings suggests that, as sonication time is extended, a higher portion of $\mathrm{Pd}$ on the surface is below the detection limits of EDX. For example, the samples prepared after 10 and 60 min ultrasound contain 4.13 and $4.14 \mathrm{wt} \% \mathrm{Pd}$, respectively, which are almost identical. The corresponding EDX readings, however, decrease significantly for the same samples from 7.39 to $4.17 \mathrm{wt} \%$. This difference is due to a greater portion of Pd nanoparticles in the ultrasound irradiated catalysts, which are detected in solution by ICP-OES but are not seen on the solid catalyst using EDX. Consequently, it appears that during the sonication process the clusters formed are progressively broken down into smaller particles, which accounts for the apparently lower metal loadings. On the other hand, the results obtained from ultrasound-assisted IW, when compared to the standard protocol, suggest that the high EDX Pd loading achieved in the control sample is due to poor metal distribution and the formation of agglomerates. Note that, on average, samples loaded using the
IW technique exhibited higher average content than those obtained after IE (Table 1). The catalytic activity, Fig. 6, increases with sonication time, with $\mathrm{CH}_{4}$ and $\mathrm{CO}_{2}$ conversions of $66 \%$ after $60 \mathrm{~min}$ of ultrasound exceeding the control sample by nearly $15 \%$. Catalysis results are consistent with ICP-OES and EDX observations showing significant improvements in both metal distribution and catalytic activity, making ultrasound-assisted IW a valuable alternative to the standard method. Nevertheless, $\mathrm{CH}_{4}$ and $\mathrm{CO}_{2}$ conversions obtained by IW loaded samples are lower than those for IE, especially when considering the relative metal loading levels. Moreover, based on the $\mathrm{CH}_{4}: \mathrm{CO}_{2}$ conversions, all samples revealed 1:1 molar ratios of the reactants suggesting limited, if any, side reactions.

Table 2 BET surface areas, ICP-OES, EDX $(N=5)$ average metal loading and standard deviation (SD) for IW preparations

\begin{tabular}{cllll}
\hline & $\begin{array}{l}\text { BET surface } \\
\text { area }\left(\mathrm{m}^{2} \mathrm{~g}^{-1}\right)\end{array}$ & ICP-OES (wt\%) & EDX (wt\%) & SD \\
\hline $\begin{array}{l}\text { Control IW } \\
\text { sample }\end{array}$ & $78.49 \pm 0.52$ & 3.32 & 11.12 & 4.40 \\
$\begin{array}{l}\text { Ultrasound }(\mathrm{min}) \\
10\end{array}$ & $34.57 \pm 1.7$ & 4.13 & & \\
20 & - & 4.33 & 7.39 & 3.52 \\
30 & $68.06 \pm 0.49$ & 2.72 & 6.45 & 3.55 \\
40 & $108.41 \pm 0.31$ & 3.18 & 6.29 & 2.61 \\
50 & $71.71 \pm 0.81$ & 2.96 & 5.82 & 2.62 \\
60 & $78.06 \pm 0.40$ & 4.14 & 5.10 & 2.66 \\
$\mathrm{pH}$ study & & & 4.17 & 2.52 \\
2 & $72.38 \pm 0.48$ & - & & \\
4 & $104.01 \pm 0.70$ & 1.84 & 3.44 & 2.24 \\
6 & $74.80 \pm 0.55$ & 1.99 & 2.42 & 0.54 \\
8 & $78.81 \pm 0.47$ & 1.95 & 4.66 & 2.78 \\
10 & $57.07 \pm 0.58$ & 1.54 & 2.41 & 1.04 \\
12 & $51.44 \pm 0.35$ & 1.01 & 2.05 & 1.16 \\
\hline
\end{tabular}

Endash (-) represents insufficient sample

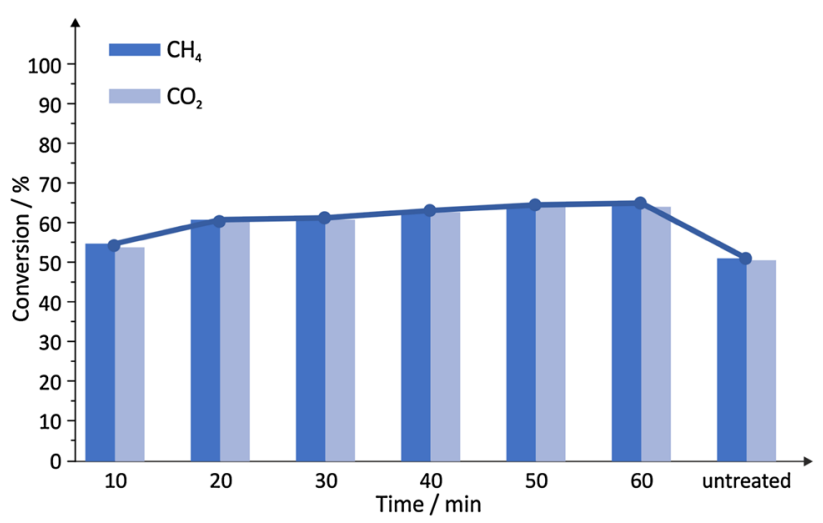

Fig. 6 DRM of ultrasound-assisted IW doped catalysts 


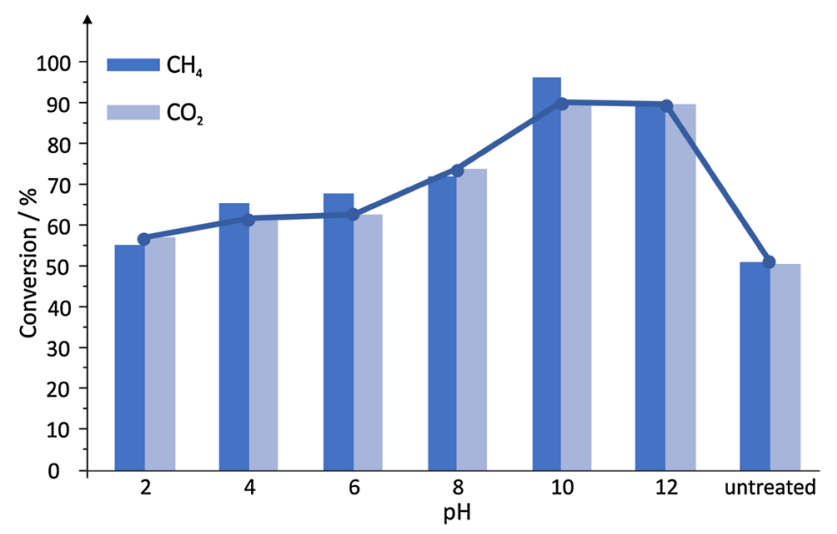

Fig. 7 DRM of IW doped catalysts at pre-treated HAP fabricated using different $\mathrm{pH}$

Finally, HAP was pre-treated before being doped with Pd using a Britton-Robinson buffer and different pHs (2, 4, 6, 8,10 and 12). Regarding the DRM reaction over pre-treated materials, in Fig. 7 it is clearly demonstrated that $\mathrm{pH}$ treatments are beneficial in terms of catalytic performance when compared to the control sample. $\mathrm{CH}_{4}$ and $\mathrm{CO}_{2}$ conversions ranged from $57 \%$ in acid to the highest value of $97 \%$ at $\mathrm{pH}$ 10 , which significantly exceeds the activity of the untreated sample. The higher catalytic activities of buffer pre-treated HAP catalysts is attributed to increased Pd distribution. As with the catalysts prepared by IE, the differences between EDX and ICP-OES metal loading values for the pre-treated samples, Table 2, are lower than those for the control, which is due to the greater share of Pd nanoparticles in the buffer treated catalysts (below EDX limits), resulting in higher catalytic activity in DRM. The catalyst showing the highest activity is the sample treated at $\mathrm{pH} \mathrm{10,} \mathrm{which} \mathrm{is} \mathrm{the} \mathrm{same}$ $\mathrm{pH}$ utilised during the synthesis of HAP; a similar result was observed for the IE method.

It is noteworthy, that the $\mathrm{CO}_{2}$ conversions vary from $\mathrm{CH}_{4}$ of the same sample, depending on $\mathrm{pH}$ utilised during IW process. The untreated sample and the catalyst prepared at $\mathrm{pH} 12$ exhibited the same response with 1:1 molar ratio suggesting limited side reactions, while catalysts treated at different $\mathrm{pH}$ varied. In cases where the conversion of $\mathrm{CH}_{4}>\mathrm{CO}_{2}$, thermal cracking of methane may have occurred along with DRM. On the other hand, in the case of samples when $\mathrm{CO}_{2}$ conversions exceeded $\mathrm{CH}_{4}$, the production of syngas may have been influenced by the simultaneous occurrence of the reverse water-gas shift reaction (Eq. 3) [14].

$\mathrm{CO}_{2}+\mathrm{H}_{2} \leftrightarrow \mathrm{CO}+\mathrm{H}_{2} \mathrm{O}, \quad \Delta \mathrm{H}=+41 \mathrm{~kJ} \mathrm{~mol}^{-1}$

\section{Conclusions}

This paper has explored the influence of ultrasound and $\mathrm{pH}$ media during IE and IW doping processes on the metal distribution and consequent catalytic activity towards DRM. Carbon nanorods were utilised as a hard-template to synthesise mesoporous HAP. The HAP was identified by TEM as having characteristic lattice structure, with a surface area of $97.57( \pm 1.16) \mathrm{m}^{2} \mathrm{~g}^{-1}$ obtained using BET. XRD confirmed the hexagonal $\mathrm{P}_{3} / \mathrm{m}$ structure. Ultrasound was employed to assist the standard IE and IW procedures and Pd distribution on the resulting samples was investigated via ICP-OES and EDX. All samples were also evaluated for the catalytic activity towards DRM. Metal distribution throughout the samples after ultrasound-assisted IE remained stable and catalytic activity decreased by $20 \%$, most likely due to the formation of agglomerates. However, ultrasound significantly accelerated the IE process from 3 days to $3 \mathrm{~h}$ and kept a homogenous metal distribution. Similar observations were made on IE samples at different $\mathrm{pH}$ values, where stable Pd dispersion on HAP was obtained. Nevertheless, in alkaline media $\mathrm{CH}_{4}$ and $\mathrm{CO}_{2}$ conversions decreased when compared to standard IE procedure that takes place in neutral $\mathrm{pH}$. Otherwise, ultrasound-assisted IW considerably improved both metal distribution and catalytic activity (by nearly 15\%) of the resulting materials when compared to the standard IW protocol. Additionally, pre-treatment of HAP at different $\mathrm{pH}$ values appears to promote homogenous metal loading, substantially enhancing $\mathrm{CH}_{4}$ and $\mathrm{CO}_{2}$ conversion by $40 \%$ at $\mathrm{pH} 10$. Finally, the physical and chemical treatments described herein are easy adaptable and offer powerful alternatives to standard doping methodologies that overcome irregular metal distribution and make the material more reliable for real applications.

Acknowledgements The authors are grateful to G-Volution Plc. for their support and contributions to this research. The authors are also thankful to Dr. H. Andrews at Manchester Metropolitan University for technical support in EDX analysis. E. Bernalte acknowledges funding from Junta de Extremadura (Spain, PO 14021).

Open Access This article is distributed under the terms of the Creative Commons Attribution 4.0 International License (http:// creativecommons.org/licenses/by/4.0/), which permits unrestricted use, distribution, and reproduction in any medium, provided you give appropriate credit to the original author(s) and the source, provide a link to the Creative Commons license, and indicate if changes were made.

\section{References}

1. Sugiyama S, Minami T, Higaki T, Hayashi H, Moffat JB (1997) Ind Eng Chem Res 36:328-334

2. Dlugokencky EJ, Nisbet EG, Bousquet P (2014) Science 31:493-495

3. Iglesia E (1997) Appl Catal A 161:59-78

4. Han Q, Fu S, Zhang X, Lin S, Huang Q (2016) Tetrahedron Lett $57: 4165-4169$ 
5. Pineiro M, Dias LD, Damas L, Aquino GLB, Calvete MJF, Pereira MM (2017) Inorg Chim Acta 455(Part 2):364-377

6. Wang X, Xu J, Qi G, Wang C, Wang W, Gao P, Wang Q, Liu X, Feng N, Deng F (2017) J Catal 345:228-235

7. Karpińska M, Skupińska J, Baran P (2009) J Mol Catal A 303:43-51

8. Veige AS (2008) Polyhedron 27:3177-3189

9. Sokolov S, Radnik J, Schneider M, Rodemerck U, (2017) Int J Hydrogen Energy (In Press)

10. Usman M, Wan Daud WMA, Abbas HF (2015) Renew Sustain Energy Rev 45:710-744

11. Osman AI, Abu-Dahrieh JK, Laffir F, Curtin T, Thompson JM, Rooney DW (2016) Appl Catal B 187:408-418

12. Oh SC, Wu Y, Tran DT, Lee IC, Lei Y, Liu D (2016) Fuel 167:208-217

13. Baktash E, Littlewood P, Schomäcker R, Thomas A, Stair PC (2015) Appl Catal B 179:122-127

14. Horn R, Schlögl R (2015) Catal Lett 145:23-39

15. Park JH, Cho JH, Kim YJ, Kim ES, Han HS, Shin CH (2014) Appl Catal B 160-161:135-143

16. Marra L, Wolbers PF, Gallucci F, Annaland MVS (2014) Catal Today 236(Part A):23-33

17. Tao K, Shi L, Ma Q, wang D, Zeng C, Kong C, Wu M, Chen L, Zhou S, Hu Y, Tsubaki N (2013) Chem Eng J 221:25-31

18. Zhu Y, Barat R (2014) Chem Eng Sci 116:71-76

19. Zhou L, Guo Y, Kameyama H, Basset J-M (2014) Int J Hydr Energy 39:7291-7305

20. Kim KH, Lee SY, Yoon KJ (2006) Korean J Chem Eng 23:356-361

21. Pinilla JL, de Llobet S, Suelves I, Utrilla R, Lázaro MJ, Moliner $\mathrm{R}$ (2011) Fuel 90:2245-2253

22. Ren H-P, Hao Q-Q, Wang W, Song Y-H, Cheng J, Liu Z-W, Liu Z-T, Lu J, Hao Z (2014) Int J Hydr Energy 39:11592-11605

23. Shang Z, Li S, Li L, Liu G, Liang X (2017) Appl Catal B 201:302-309

24. Singha RK, Yadav A, Agrawal A, Shukla A, Adak S, Sasaki T, Bal R (2016) Appl Catal B 191:165-178

25. Singha RK, Shukla A, Yadav A, Sivakumar Konathala LN, Bal R (2017) Appl Catal B 202:473-488

26. Meejoo S, Maneeprakorn W, Winotai P (2006) Thermochim Acta 447:115-120

27. Opre Z, Grunwaldt JD, Maciejewski M, Ferri D, Mallat T, Baiker A (2005) J Catal 230:406-419

28. Boukha Z, Ayastuy JL, González-Velasco JR, Gutiérrez-Ortiz MA (2017) Appl Catal B 201:189-201
29. Chlala D, Labaki M, Giraudon J-M, Gardoll O, DenicourtNowicki A, Roucoux A, Lamonier J-F (2016) Comptes Rendus Chim 19:525-537

30. Rêgo De Vasconcelos B, Zhao L, Sharrock P, Nzihou A, Pham Minh D (2016) Appl Surf Sci 390:141-156

31. Xu J, Xu X-C, Yang X-J, Han Y-F (2016) Catal Today 276:19-27

32. Özhava D, Özkar S (2015) Int J Hydr Energy 40:10491-10501

33. Huang C, Ma Z, Xie P, Yue Y, Hua W, Gao Z (2015) J Mol Catal A 400:90-94

34. Qu Z, Sun Y, Chen D, Wang Y (2014) J Mol Catal A 393:182-190

35. Indra A, Gopinath CS, Bhaduri S, Kumar Lahiri G (2013) Catal Sci Technol 3:1625-1633

36. Jaworski JW, Cho S, Kim Y, Jung JH, Jeon HS, Min BK, Kwon K-Y (2013) J Colloid Interface Sci 394:401-408

37. Rakap M, Özkar S (2011) Int J Hydr Energy 36:7019-7027

38. Sugiyama S, Minami T, Moriga T, Hayashi H, Moffat JB (1998) J Solid State Chem 135:86-95

39. Mori K, Hara T, Mizugaki T, Ebitani K, Kaneda K (2004) J Am Chem Soc 126:10657-10666

40. Neelakandeswari N, Sangami G, Emayavaramban P, Karvembu R, Dharmaraj N, Kim HY (2012) Tetrahedron Lett 53:2980-2984

41. Sudhakar M, Kumar VV, Naresh G, Kantam ML, Bhargava SK, Venugopal A (2016) Appl Catal B 180:113-120

42. Kamieniak J, Bernalte E, Foster CW, Doyle AM, Kelly PJ, Banks CE (2016) Catalysts 6:119

43. Rakap M, Özkar S (2012) Catal Today 183:17-25

44. Okal J, Zawadzki M, Kępiński L, Krajczyk L, Tylus W (2007) Appl Catal A 319:202-209

45. Suslick KS, Skrabalak SE (2008) Sonocatalysis. In: Ertl G, Knozinger H, Schuth F, Weitkamp J (eds) Handbook of heterogeneous catalysis. Wiley-VCH, New York, pp 2007-2015

46. Shchukin DG, Skorb E, Belova V, Möhwald H (2011) Adv Mater 23:1922-1934

47. Okitsu K, Yue A, Tanabe S, Matsumoto H (2000) Chem Mater 12(10):3006-3011

48. Li J, Bai X (2016) J Mater Sci 51:9108-9122

49. Hana GH, Seoa M, Choa Y-H, Hanb SS, Lee K-Y (2017) Mol Catal 429:43-50

50. Kamieniak J, Doyle AM, Kelly PJ, Banks CE (2017) Ceram Int 43:5412-5416

51. Rujitanapanich S, Kumpapan P, Wanjanoi P (2014) Energy Proc $56: 112-117$ 